\title{
Concerning Abolitionism, Black People, and Capoeira in the History of Brazil: Social and Moral (Im)Balances
}

Authors' contribution:

A) conception and design of the study

B) acquisition of data

C) analysis and interpretation of data

D) manuscript preparation

E) obtaining funding

\author{
Ana Leticia Padeski Ferreira ${ }^{1}$ A-E , Marchi Júnior \\ Wanderley ${ }^{2 \mathrm{~A}, \mathrm{C}, \mathrm{D}}$ \\ ${ }^{1}$ CEPELS, ALESDE, DECISO / UFPR; Faculdade Guairacá, Brazil \\ ${ }^{2}$ CEPELS, ALESDE, DECISO, DEF / UFPR; WVU, CAPES, Brazil
}

The purpose of this article is to discuss the changes that took place in relation to the peculiarities of Capoeira within Brazilian society. This popular practice, which is considered a martial art, a dance and a game, developed during the $19^{\text {th }}$ century, where it was practiced by individuals from the lower walks of life. Practicing Capoeira was a felony, as it posed a threat to public safety, order, and morality. Presently, it has been upgraded to a Brazilian cultural asset, which shows how the perception of its practice has changed. These changes follow the different views of the historical processes related to abolitionism and the perverse incorporation of blacks into society at that time, which have continued until present time, having undergone significant changes and grown as a valued physical expression.

capoeira, Brazil, cultural asset, abolitionism

\section{Introduction}

The abolition of slavery was a process that underwent different moments and consequences. A specific group of Brazilian society at that time - the abolitionists - perceived slavery as a "festering sore" and as a situation that held back the development of Brazil. Scholars would analyze the situations at hand and proposed possible solutions for the future of the country. This article presents and discusses how the abolitionism process impacted Brazilian society and how the freed slaves were brought into this new mindset, based on the arguments provided by Florestan Fernandes and Thomas Skidmore. Finally, this study addresses how the moral imbalance of the freed slaves suffered a perverse trajectory for their inclusion, which resulted in a list of unfavorable characteristics for these individuals and their customs, e.g. the legal prohibition of Capoeira in 1890.

\subsection{The abolition of slavery: a necessity}

A group of Brazilians - the abolitionists - realized that it was necessary to put an end to this form of work, as it was harmful both for the slaves and for Brazil. In his representation at the Constituent and Legislative General Assembly of the Empire of Brazil, Silva (1998) proposed measures for the nation's prosperity, focusing on the discussion of a new law for trading and treating slaves. The author advocated 
abolishing this type of trading and work regime, improving the lives of individuals that lived under that regime, and fostering their gradual emancipation.

Another argument supported by Silva (1998) was that the introduction of new slaves into Brazil would hinder industrial development that was based on individual freedom, capitalism, a free workforce, etc. This was because the slave owners that employed a slave workforce did not engage in the proactive endeavors required for this new enterprise to prosper.

The logic behind slavery also held back the development of paid workers in other fields, such as commerce. Nabuco (1999, p. 177) admonished:

"Slavery is not conducive to creating any type of working class nor is compatible with paying wages and the personal dignity of the worker. The latter, in order to distance himself from the social stigma that slavery puts on workers, tries to make it clear to society that he is not a slave and takes on a feeling of superiority, which is in fact a sign of low spiritual values of those who have just stepped up from the menial condition, or experienced it through their parents. Furthermore, there is no such thing as a strong, respected and intelligent working class when the individuals that hire these workers are used to overseeing slaves. Brazilian workers, on turn, also fail to exercise a minimum of political influence".

National patriotism was another factor affected by slavery, which was not displayed as such, but rather as the patriotism of a race, typical of a certain group. Instead of uniting the people of the same nation, this mindset separated them and set up different barriers. In order to drive national cohesion, the slave would have to experience the feeling of personal independence and perceive his or her importance in society as a true citizen and an active and critical unit in the nation to which they belonged (Nabuco, 1999).

Without any national awareness it was also more difficult to form public opinion and the means to disseminate it. Without new ideas and innovation, public opinion becomes impervious to progress. Nabuco (1999, p. 190) reinforced the belief that "public opinion [...], is in itself the educated, moral, and patriotic national consciousness; it is impossible to coexist with slavery, and should it emerge, slavery immediately will destroy it".

The structures and dispositions of a society that supports slavery compared to an industrial society are dramatically different, according to Nabuco (1999). The former thwarts initiative, invention and individual energy, all of which are important for the latter, and are the required elements for entrepreneurship, e.g. association and capital, abundant work, technical education for the workforce and confidence in the future, without which the industrial milieu and commerce cannot thrive.

After Brazil joined the competitive world market still holding these traditional social and moral elements, it would undergo a process of perverse modernization; it became divided between a line of thinking that denied traditional values and proposed a new logic, where the former were not abandoned, thus hindering the full development of both processes.

However, the abolition of slavery could not occur if the needs and reinsertions of those individuals were not provided for under a social logic unbeknownst to them. Silva (1998) calls attention to this process that would culminate in the emancipation of the freed slave.

This gradual process mentioned by Silva (1998) would foster both the physical and civil homogeneity that would enable greater national cohesion. Hence, the author acknowledges the slave as a human being who could possibly have the same civil status as the white man, and no longer be considered a commodity.

\subsection{From slaves to blacks: moral inadequacy and (bio) social stigmas}

In a scenario that envisaged the abolition of slavery, there were two processes already in the horizon: 1. The intention was not just to free the slaves, but also to oppose the previous regime as a whole. Thus, despite the participation of the blacks - that was intense - but due to the mindset of ignorance that prevailed, they were reduced to mere puppets. It was demanded more than merely their freedom, but only a required 
preliminary condition; 2. In the end, the structure and dynamics of the Brazilian economy imposed this trajectory on the dominant classes. Slaves became a costly commodity; the organization of labor was changing, and new agents would join the ranks that would provide services for their owners.

According to Fernandes (2008), the end of slavery did not provide free blacks any assistance in the transition that would take place. Slave owners were not held accountable for providing maintenance and sustenance for this group of individuals that were unprepared to join the ranks of the free workforce, nor was there any other institution that would step up to this responsibility. Hence, "the freed slave suddenly and abruptly became his own matter, responsible for both himself and those who depended on him despite lacking the material and moral means to do so [...]" (Fernandes, 2008, p. 29).

Their fate was only considered while they affected the future of the crops, during the period that preceded the abolition of slavery. When this labor regime was banned, slave owners turned their attention to their own interests, where slaves had no place. The political measures taken during this period of transition addressed the farming crisis. The situation of blacks was never addressed by measures put in place by the public power (Fernandes, 2008).

Skidmore (1976) addressed the situation of slave owners when slaves were freed. The law was passed without providing any means of compensation for the owners, and it was only enforced due to the flexibility of the former slave owners in finding an alternative workforce that would preserve their public power. Hence:

"As those keen landowners has already predicted, the abolition of slavery did not bring the social and economic changes envisaged by the abolitionists, who were more naïve than the landlords. Brazil was created as an agriculture-based country, where the paternalistic system prevailed also in urban areas. It was a social stratification system that bestowed on white and occasionally on light-skinned mulato landowners the actual monopoly of power - economic, social and political. The population from the lower walks of life, including poor white people and most of the freed slaves were used to being submissive and respectful. This type of hierarchy that was strongly based on the color of the skin developed as an ingrained part of the Colonial slave-based economy. However, in the days of the Abolition, it no longer depended on slavery in order to continue" (Skidmore, 1976, p. 54).

The owners of large farms realized before the abolition of slavery that they no longer needed a slave workforce in order to maintain their economic and social control. Once they were free, slaves would become part of a social, multi-racial, and paternalistic society that kept the social and power scales pending in favor of the landowners, where free blacks could only be deferent to the upper strata in a pre-industrial system (Skidmore, 1976). However, Fernandes (2008) points out that the process for blacks was differentiated and perverse, in that they found themselves in a society that was becoming modern and changing the manner of social relations. Paternalism and other values inherent to the traditional way of life had no place in this modern society. Without the moral apparatus that was based on traditional values and with the limitations to find another occupation to provide for them and their families, blacks began their trajectory from the worst possible point.

The city played an important role in the degradation of servitude, since it was in major urban centers that an unfavorable opinion was formed in relation to the fundamentals of slavery, and acted in favor of the slaves' freedom. Only in big cities were there individuals with enough economic, social, and political autonomy to oppose the interests inherent to slavery and to act against them. Therefore, slaves sought those venues when they ran away or were freed, as they needed safe haven, protection, and guidance. The "[...] city stood as a symbol and promise of freedom" (Fernandes, 2008, p. 84).

The nefarious effects of slavery became evident after its abolition: social turmoil, hoards of free slaves trying to live off the land returning to their former masters in order to work, migration to cities that were unprepared to accommodate such a large, unskilled workforce. The result was the formation of bands of free blacks as urban outcasts: the Capoeira players. They became a threat to law and order, where Capoeira was 
considered a felony under the Penal Code of 1890, thus strengthening the image that blacks were backward individuals lacking in the required social skills, stressing the need to 'whitewash' the country in order to get rid of the dead weight posed by these individuals (Skidmore, 1976).

At that time, Brazil had a pluralist and multi-racial social system. It was a more complex social structure due to miscegenation, as mentioned above, where social appearance and wealth were forms of identifying a person as being from a less or more privileged walk of life. Skidmore (1976) exemplifies this situation when he uses the maxim: money whitewashes. Thus, phenotypic traces that could be revealed when an individual proved he or she had power and influence. This status was protected by hiding their background and maintaining a facade.

"This behavior implies that mulatos with the 'right' phenotypic traces to give them the desired social acceptance were yet capable of feeling insecure to the point of fearing that their life in society could be threatened with a change in status due to their family background" (Skidmore, 1976, p. 56).

The limits of this social mobility depended on an individual's appearance and their cultural capital, e.g. the whiter, both physically and socially, the greater their chances of social ascension. Hence, the forms differentiating social groups and strata became more complex, where society called for a keen sensitivity in order to identify the differences and manage the tension (Skidmore, 1976).

Despite the multi-racial aspect and the proximity of different ethnic groups, Brazilian society was fundamentally racist, where the white man stood at the top of the social pyramid. This mindset fostered the ideal of 'whitewashing' the nation, advocating that it was necessary to increase the number of light-skinned people, who would then drive the country's progress (Skidmore, 1976).

One can observe that in order to organize its strata, society at that time resorted to biological traces, i.e. color of the skin, in order to establish social differentiation. A certain genetic trace would impart the stigma of slavery and of being black, where the color of the skin was responsible for traits such as being indolent, a bum, and unruly. It is interesting how this transposition was carried out to make the racist discourse legitimate, where the white man was superior, both biologically and socially.

Addressing the migration of the blacks to the cities after the abolition of slavery, particularly in the case of São Paulo, Fernandes (2008) attests that there were influences to the quick assimilation of the blacks into the competitive social order, in addition to the aforementioned ones, that occurred especially in the historical scenery of São Paulo: 1. Quick urban expansion and the progress of the agrarian civilization; the late start of Colonial export in São Paulo - which occurred when slavery was already in crisis - the difficulty of the freed slave being included in the job market niche progressing in the competitive social order, where their occupations were also more modest and less rewarding. 2. The freed slave also had to overcome the competition of immigrants before they could find a job, now in the city rather than in the field, where the newcomers lacked the same resilience for underpaid work, as they knew it would be a temporary situation. This was not the case of the freed slaves, who sought an occupation unlike forced labor. 3. São Paulo was the city most unlikely to absorb the recently free blacks because it was a bourgeois urban center with a mercantile mindset, the fundamentals of which (individual freedom, free job opportunities, and economic liberalism) did not meet the reality so far experienced by the former slaves, making their inclusion difficult (Fernandes, 2008).

Fernandes (2008, p. 34) suggests that the blacks:

"became misfits and outcasts in a turbulent scenario forged thanks to the 'coffee fever'. Even when they were included in the urban job market they were not guided toward the future and for this reason would not 'take off'. They lacked the necessary courage to take on degrading jobs, unlike the Italians who would shine shoes, sell fish and newspapers, etc.; they were not 'industrious' enough to foster the savings schemes, which were constructed based on a series of apparently indecorous deprivations and to use them as a launching pad for wealth and 'success'; [...] and above all, they were not driven by the desire for the power of accumulated 
wealth. Wherever they occupied dignifying positions (as independent artisans or traders of meats and baubles), where they conquered a promising occupation (as a civil servant and free workforce, per task or permanently, they would invariably embrace models of pre anti-capitalist models" (Fernandes, 2008, pp. 34-5).

Hence, it becomes evident that the psychosocial and economic conditions that arose under the order of competiveness did not correspond to the pre-capitalism conditions that were the milieu in which blacks had been included until then. Deformation caused by life as a slave also limited the adaptation of those individuals to city life, hindering the opening of new possibilities under this new social order. Fernandes (2008, p. 35) notes that Brazilian society "[...] left the blacks to their own demise [...]", where they were accountable to change in order to meet the new standards and ideas created by the social capitalist order that was based on free workforce and the republican regime. However, blacks did not have the means to make that change, as they never had been their own masters.

Another factor that fostered the inadequacy of urban life for blacks was that São Paulo was an inhospitable venue for their inclusion, as it had never had strong ties with a rural past. It was at the border stage between province and city, i.e. it was no longer proud of the old customs and still had many provincial traces to break away from those customs and adopt an urban lifestyle. Blacks and mulatos were not able to enjoy the advantages of an urban center, i.e. the possibility of cultural isolation, tolerance and a mass job market, as well as take advantage of the city's provincial aspects that fostered social stability, traditional concepts, and compensations ensuing from a subsistence economy (Fernandes, 2008).

This situation deeply affected both blacks and mulatos, since they were kept from perpetuating their slave-related cultural heritage and were hampered by traditionalism that had lost its purpose. Fernandes (2008, p. 85) gives the following example of this aspect:

"Both aspects are related structurally and dynamically to the fate of the blacks and the mulatos in that urban environment. Even police-related measures were taken to prevent the nightly 'reviviscence' of 'old customs' that would disturb peace and perhaps the decorum of the white population. However, cultural losses ensuing thereof were never compensated with the acquisition of alternative cultural values".

Another peculiar element of the urban life of blacks was the hard time they had in finding a job, depending on the number of women for whom they had to provide sustenance. Black women often had more contact with the master's household, where they did work that was needed in the city, such as looking after a house and cooking. Due to this situation, many men would neglect the importance of holding a job that would provide them the means of providing for themselves and their family; thus, as a rule they depended on the womenfolk to eat, live, and for the daily expenses. The continuity of this condition gave them more free time, as they had no responsibilities. Many men were totally idle and sought the company of other men in the same situation to enjoy a leisurely time in public venues, mainly taverns. This led to the growing demoralization of blacks (Fernandes, 2008).

\section{Capoeira: a punishable crime}

Capoeira is a form of physical exercise that is currently broadly defined. Considered a fight, a dance and a game, it is nowadays an important cultural asset of Brazil (Lussac \& Tubino, 2009). Different authors describe how hard it is to identify its starting point. Lussac and Tubino (2009) identify a possible starting date of Capoeira based on the oldest document dated from the first decade of the 19th century in Rio de Janeiro. Other references to Capoeira can also be found in police records. The authors add:

"During the nineteenth century, Capoeira quickly developed in the urban milieu. In the beginning of that century, according to Soares (2002), most Capoeira players in the city of Rio de Janeiro were slaves and Africans. However, according to Rocha (2002, p. 12), Antônio Moraes da Silva mentions 'Capoeira Fighting' as it was practiced by the blacks, half-breeds and indigenous people in Brazil in his book 'Dicionário da Língua Portuguesa' (Dictionary of 
the Portuguese Language), edited in Lisbon on 1813, where it is possible that Capoeira was practiced at that time not only by the blacks, but also by half-breed and the indigenous people" (Lussac \& Tubino, 2009, p. 8).

Silva (2001) considers the period of slavery as the beginning of this practice in Brazil. The author affirms that the contact with different ethnic groups also modified their cultural elements, thus reshaping it. Capoeira would come to be in this period; later, it would become a popular manifestation of Brazilian culture.

During the days of slavery, Capoeira was a popular practice, a manifestation that fostered the gathering and organization of the captives, which the police called "bands".

"These bands were rivals and fought for political and public control in the city. They were paramilitary organizations that for sure threatened current social order. Furthermore, they followed different philosophical lines. Quite the contrary, their confrontations ensued mainly from their political differences, where some openly supported the republican cause and others were monarchists. There were also members of these organizations that had no defined political allegiance, preferring to keep neutral and wait for any event from which they could obtain political or financial advantages" (Silva, 2001, p. 134).

After the abolition of slavery, Capoeira was practiced by freed slaves, European immigrants, and halfbreeds from the working classes. In the second half of the $19^{\text {th }}$ century, Capoeira aficionados included individuals from the upper classes, such as the Portuguese, military, and members of the elite (Lussac \& Tubino, 2009).

Under the Penal Code of 1890 (Brazil, 1890) Capoeira was considered a felony, alongside crimes against the nation, conspiracy, escaping from prison, disobeying the authorities, crimes perpetrated against public health, personal freedom, the free association of cults, domestic abuse, crimes perpetrated against public faith, smuggling, physical violence, kidnapping, adultery and homicide, to mention but a few. As mentioned above, Fernandes (2008) states that right after the abolition of slavery, blacks were forbidden to meet in groups, which was the case of Capoeira. Society feared for public safety, order and the morality of customs, which encouraged Capoeira to be considered a crime because it was a form of fighting associated to the stereotype of lazy and vagrant individuals. This situation also brought in as evidence a moral imbalance, where the blacks did not share the same capitalist values of the white man, creating and reinforcing the aforementioned stereotypes.

Lussac and Tubino (2009, p. 9) affirm that at the time of:

"the Proclamation of the Republic, [...] a new course was proposed for the national politics, and consequently and above all, for capital. There were new ideals, projects, interests, stands and attitudes by the new administration, and Capoeira would be one of the main new targets for repression until it was totally banned, where its practice on streets and public parks was forbidden under the Penal Code of 1890".

With the prohibition, groups would practice Capoeira clandestinely, whereby it became associated with scoundrels. Given that it is permeated with elements that identified its aficionados, which were modified by conflict, Capoeira retains the history, traditions and roots of the cultures that created it. Prohibition was a means of annihilating the organization and the identity of a segment of society (Castro Júnior, 2004).

After a certain period of time had lapsed after the abolition of slavery, blacks were no longer regarded as a source of imminent danger (Fernandes, 2008). However, due to the stereotype already ingrained in society's mind, this group was still regarded with suspicion, which reflected on Capoeira. It can be thought that individuals from the upper classes took up Capoeira much later due its social implications, a custom typical of blacks. 
Mello (2002, p. 32), suggests:

"It is important to note that Capoeira was created both as an instrument of physical resistance and as a cultural resistance movement, as well as from the need of the blacks to rebuild their identity as human beings. According to Schwarcz (1997), the blacks had to reinvent their own existence in order to adapt to their new reality. In this sense, Capoeira fighting became a manifestation of resistance where their symbolic and motor universe was laden with elements of their African ancestral culture, e.g. religion, music, movements, customs, etc. However, these elements were not presented in an original manner, but rather were readapted to the new imposed social contingency".

Under this scenario, in addition to the banning of Capoeira, blacks and mulatos had their traditions changed by the white man, as they lacked the control to preserve and enjoy their cultural values. Capoeira was one such practice conducive to the personal and collective affirmation of the blacks via an organized social life. This event reveals two elements: 1. Cities were oriented towards a type of economic and sociocultural growth that had no room for the cultural heritage of blacks, which could have helped; 2 . This orientation was not strong, involving or sufficiently adaptable to produce similar effects, leading to the perpetuation of anti-urban traditional culture - characteristics that caused the hindering and inertia of blacks in the cultural history of the city (Fernandes, 2008).

With the psychosocial and economic conditions that arose with the competitive social order, we notice in the text by Fernandes (2008) that it did not correspond to the conditions of pre-capitalism - an organization wherein blacks were included. The morals and values, as well as how they perceived themselves - acquired while still slaves - limited their inclusion and adaptation to this new condition. Left to their own demise, blacks sought elements of their culture, among which was Capoeira, in order to establish a group identity that encompassed religion, ancestry, and other cultural elements. However, these possibilities were thwarted due to their lack of freedom, such as the prohibition of playing Capoeira and of meetings of practitioners. This typical cultural manifestation was also deformed to the point of not being recognized by blacks.

The escalating demoralization of blacks ensuing from the shortage of jobs and the greater opportunity of work for women, which was similar to what they did as slaves, caused the white population to create a series of stigmas for this group, i.e. bum, lazy, and attached to traditional customs. This profile had no place in the city that was opposed to the traditional values and was not able to provide the cultural isolation that blacks would need to maintain their culture. This deeply affected the blacks and the mulatos, as the perpetuation of their slavery related cultural heritage was forbidden and became excessively associated with the traditional ways.

\section{Final considerations}

The purpose of this article was to bring together scholars of the Brazilian Social Mindset with Capoeira. This approach has proved to be advantageous, as there are few studies on this theme, and converging the theories with the subject matter is not usual.

The criminalization of Capoeira is a significant indicator of the position occupied by the blacks in the post-abolition society. There was fear of violence that might be perpetrated by this group right after they became legally free; it is noticeable that they also had to face deep misconceptions in relation to the social logic of that time. Furthermore, attempts at forbidding the blacks to create a group identity conducive to the aforementioned inclusion can be identified in the prohibition of Capoeira and public meetings.

At that time, society had a disparaging perception of blacks, where stigmas related to their behavior due to their inadequacy and demoralization were associated to the fact that menfolk could not provide for their families, and a suspicion that their women were relying to prostitution to maintain their family, who actually worked for white households. These characteristics permeated not only individuals, but also their 
culture and customs, one of which was Capoeira. To legitimize this perception, the white man resorted to science, associating these characteristics to a biological feature - the color of the skin.

Therefore, this study hopes to give its contribution to the studying of Capoeira that lacks research and critical references, relating the social context to practice in a more comprehensive manner.

\section{REFERENCES}

Silva, J. (1998). Projetos para o Brasil /Projects on Brazil/. São Paulo: Companhia das Letras.

Nabuco, J. (1999). O Abolicionismo /Abolitionism/. Rio de Janeiro: Nova Fronteira.

Skidmore, T. (1976). Preto no branco: raça e nacionalidade no pensamento brasileiro /Black in White: race and nationality in Brazilian thought/. Rio de Janeiro: Paz e Terra.

Fernandes, F. (2008). A integração do negro na sociedade de classes: o legado da "raça branca" The integration of blacks in a class society: the legacy of the "white race"/. São Paulo: Globo.

Lussac, R., \& Tubino, M. (2009). Capoeira: a história e trajetória de um patrimônio cultural do Brasil /Capoeira: the history and path of a cultural heritage of Brazil/. Revista da Educação Física /Physical Education Journal/, 20(1), 7-16.

Silva, P. (2001). Capoeira e Educação Física - uma história que dá jogo... Primeiros Apontamentos sobre suas Interrelações /Capoeira and Physical Education - a playable history... Early notes on their interrelationships/. Revista Brasileira de Ciências do Esporte /Brazilian Journal of Sports Sciences/, 23(1), 131-45.

AUTHOR'S ADDRESS:

Ana Leticia Padeski Ferreira

Rua Guilherme Seeger, 580

Curitiba, Paraná - Brasil

CEP: 80520-420

Email: analeticiaferreira@gmail.com 